\title{
Intraday Volatility Analysis on S\&P 500 Stock Index Future
}

\author{
Hong Xie \\ Centre for the Analysis of Risk and Optimisation Modelling Applications \\ Brunel University, Uxbridge, UB8 3PH, London, UK \\ Tel: 44-189-526-6387Ｅ-mail: Hong.Xie@Brunel.ac.uk \\ Jian Li \\ Centre of Intelligent Data Analysis \\ School of Information Systems, Computing and Mathematics \\ Brunel University, Uxbridge, UB8 3PH, London, UK \\ Tel: 44-189-526-5986Ｅ-mail: Jian.Li@brunel.ac.uk
}

\begin{abstract}
This paper analysed intraday volatility by S\&P 500 stock index future product and basic on the high frequency trading strategy. The processes of the model are the GARCH series which including GARCH $(1,1)$, EGARCH and IGARCH, moreover run such models again by GARCH-In-Mean process. The result presented that EGARCH model is the preferred one of intraday volatility estimation in S\&P500 stock index future product. And IGARCH Model is the better one in in-the-sample estimation. Otherwise the IGARCH model is the preferred for estimation in out-of sample and EGARCH model is the better one. GARCH $(1,1)$ model haven't good performance in the testing. Overall the result will engaged in microstructure market analysis and volatility arbitrage in high frequency trading strategy.
\end{abstract}

Keywords: Intraday Volatility, High frequency trading, GARCH model, Index future

\section{Introduction}

Volatility model is one of main approach using in asset return estimation. In high frequency trading field, volatility modelling applied in forecast intraday return varying, the time range almost between 1 minters to 240 minters so that the assets return estimation can be more accurate and efficiency. Current research diversify the volatility model as linear and non-linear, and the most popular and wield use is that generalized autoregressive conditional heteroskedasticity (GARCH, Bollerslev(1986)) model. Pagan and Schwert is the earlier one of apply GARCH model in estimate financial asset return volatility, they estimated stock return volatility by GARCH and E-GARCH model (Nelson (1991)). Franses and Van Dijk (1996) proposed to estimate stock return volatility of Germany, Holland, Spain, and Italy and Sweden stock exchange by non-linear GARCH models, the research result proposed that non-linear GARCH model can significantly improve the linear GARCH model efficiency in volatility forecasting. Anderson and Bollerslev (1998) used them research to confirm that GARCH series is more accurate volatility estimation model. Other hand, Admati and Pfleiderer (1988) have researched price and volume by intraday patterns, it is an earlier intraday price volatility forecast theory. Engle, Ito and Lin (1990) researched intraday volatility in foreign currency market. Bessembinder and Seguin (1993) researched the intraday price, volume and market depth by high frequency data. It is the first empirical high frequency research which focuses on future market. However, current high frequency research almost focuses on equity and foreign currency market but stock index future markets, just few papers had researched about it.

This paper I'm going to study intraday volatility analysis in S\&P 500 index future products by GARCH model series, there are GARCH $(1,1)$, E-GARCH and I-GARCH models. By the S\&P 500 historical data, and going to estimate ultra frequency, each 1 minter, 5 minters, 10 minters and 15 minters return volatilities varies for statistic volatility trading opportunities.

\section{Data and Methodology}

This paper study S\&P 500 stock index future in which is the main financial future contract in the world. The intraday data of S\&P 500 index future is obtained from TickData Company, the time period from $1^{\text {st }}$ September 2008 to $30^{\text {th }}$ September 2009. The price records are including 1 minutes, 5 minutes, 10 minutes, 30 minutes and 60 minutes sets. The logarithm returns of different times calculate as $R_{-} t=\log \left(p_{-} t / p \_(t-1)\right)$, where $p_{t}$ is the future price of the period $t$ and $p_{t-1}$ is the future price of immediately preceding period. 
The estimation of will calculate the rate of return firstly. Then test whether the rate of return exist the unit root or not by Augmented Dickey-Fuller (ADF, 1979) and Phillips and Perron (PP, 1988) models, and different the data until it is stationary if it has unit root phenomenon. In volatility forecast, first to test whether the rate of return is or not conditional variance by ARCH-LM model and then forecast the volatility in different time by GARCH-type models.

In case of financial price and return volatility has significantly heteroskedasticity feature. Generalized autoregressive conditional heteroskedasticity model is more usable in return volatility estimation field. According to (Engle (1982)), the GARCH (p, q) model can write as:

$$
\sigma_{t}=\sqrt{\alpha_{0}+\sum_{i=1}^{q} \alpha_{t} \alpha_{t-i}^{2}+\sum_{i=1}^{p} \beta_{t} \alpha_{t-i}^{2} \sigma_{t}}
$$

Where $v^{2}$ is current time conditional variance, $a$ is intercept, $\sigma_{-1}^{2}$ is the conditional variance on formal time, $\beta$ is parameter, means that the influence of old news to market volatility, $\gamma_{i}$ is parameter means that the influence of new positive to market volatility, $a_{-j}^{2}$ is sum of error square on last time and $\epsilon_{t}$ is white noise.

Normally, the price and return volatility is estimated by $\operatorname{GARCH}(1,1)$ model which is

$$
\alpha_{t}=e_{;} \sigma_{t}
$$

$$
\sigma_{1}=\sqrt{\alpha_{0}+\alpha_{1} \alpha_{i-1}^{2}+\beta_{1} \sigma_{i-1}^{2}}
$$

Volatility always has persistent changes, in this case Nelson (1990) designed Integrated GARCH (Note 1) model $(\mathrm{IGARCH})$ process. A GARCH $(\mathrm{p}, \mathrm{q})$ process is stationary with a finite variance if

$$
\sum_{i=1}^{q} \alpha_{i}+\sum_{i=1}^{p} \beta_{i} \alpha_{1}
$$

A GARCH $(p, q)$ process is called IGARCH process if

$$
\sum_{i=1}^{q} \alpha_{l}+\sum_{i=1}^{p} \beta_{l}=1
$$

In finance field, the leverage effect predicts that an asset's return may become more volatile when the price decreases. Exponential GARCG (Note 2) EGARCH) model process is designed to model the leverage effect by Nelson (1991). The model is

$$
\log \left(\sigma_{\mathrm{t}}\right)=\alpha_{0}+\sum_{\mathrm{i}-1}^{q} \alpha_{1} g\left(\sigma_{\mathrm{t}-1}\right)+\sum_{\mathrm{i}-1}^{\mathrm{p}} \beta_{\mathrm{i}} \log \left(\sigma_{\mathrm{t}-1}\right)
$$

Where

$$
g\left(\sigma_{\mathrm{t}}\right)=\theta \epsilon_{\mathrm{t}}+\gamma\left\{\sigma_{\mathrm{t}} \|-\mathrm{E}\left(\left|\sigma_{\mathrm{t}}\right|\right)\right\}
$$

In some estimations, it make sense to use the conditional standard deviation as one of regression variables, when the dependent variables is a return then we might expect that higher conditional variability causes higher returns, because the market demands a higher risk premium for higher risk. Model where the conditional standard deviation is a regression variable called GARCH-in-mean (GARCH-M) which can write as:

$$
r_{t}=X_{\tau}^{T} \gamma+\dot{s} \sigma_{t}+\alpha_{\tau}
$$

Where $\sigma_{\tau}$ is the GARCH process with conditional standard deviation process $\sigma_{t} \cdot \sigma_{t}$ and components of $X_{t}$ are the predictor variables and $\sigma$ and the components of $\gamma$ are the regression coefficients. Here $\sigma_{t}$ must be estimated.

In the process of estimation, firstly set the model for calculate square of return by as follows equation:

$$
\sigma_{i+1}^{2}=\alpha+b h_{i+1}^{2}+w_{s}
$$

Where $\nabla_{i+1}^{2}$ is the true volatility and $h_{i}^{2}$ is the volatility in forecast.

According to Pangan and Schwert (1990), function (5) will write as log form as: 


$$
\log _{2}\left(s_{t}+2\right)=a+b \log \left(h h_{i+2}\right)+u_{t}
$$

Second set the root mean square model for calculate the different between estimation and true value of volatilities, the RMS equation is

$$
R M S E=\sqrt{\frac{1}{2} \gamma_{i-1}^{2}\left(h_{i}^{2}-\sigma_{t}^{2}\right)^{2}}
$$

Where $\tau$ is the number of observations.

\section{Empirical Result \\ 1. Descriptive Statistic}

From 6 frequency descriptive statistical calculation, we knew that 1 minute unite data has the biggest value of mean standard deviation than others. And the maximum and minimum values of ultra data are biggest and lowest than others. $1 \mathrm{~min}$ data has biggest standard deviation which means that each $1 \mathrm{~min}$ value has significantly different with the mean and also the data is much more discrete. Ultra and $1 \mathrm{~min}$ unites data has left side slopes and others has right slopes and all of the data unites has the feature of leptokurtic distribution.

Insert Table 1 Here

\section{Unit Root Test}

For test the whether the data is stable, we normally test it by ADF and PP models, the hypothesis are:

$\mathrm{H}_{0} \mathrm{I}$ Unlt root $1 \mathrm{E}$ exethig

\section{$\mathrm{H}_{1}$ i Unt root is wat melther}

Table 2 shows all frequencies ejected $\mathrm{H}_{\mathbb{\Omega}}$, and then there have not unite root effect, the data series are stable.

Insert Table 2 Here

\section{Heteroskedasticity Test}

Before estimate the volatility by GARCH-type model, it is necessary to test whether the conditional heteroskedasticity is existing in variance. The hypothesises of the testing are:

\section{$\mathrm{H}_{0}$ : Nom - ARCH Hfflelency \\ H1: ARCH Efficiency}

Table 1 show all frequencies ejected $\boldsymbol{H}_{0}$. All data series has heteroskedasticity efficiency. Then the GARCH-type testing is available.

Insert Table 3 Here

\section{Realized Volatility Statistics}

From figure 1 to 6 are the realised volatilities of ultra to 60 minutes.

Insert Figure 1, Figure 2, Figure 3, Figure 4, Figure 5, Figure 6 Here

From the above figures we can easily find that the volatility clustering features in each frequency team. Otherwise in case of the number of observations are too much huge so that the clustering phenomenon maybe not analyse clearly.

\section{Forecast Results}

The following table presents the results from the forecast models which estimated by both in the sample and out of sample data. For each frequency of the data and each of forecast model the best one ranked estimation are signed as symbol of *.

Table 4 presents the results for the in the sample as the measure of realized volatility. From the results we know that GARCH $(1,1)$ model has 3 times ranked in the best model which has including GARCG -M type. EGARCH (EGARCH-M) has 4 times ranked in best estimated model and as well as 4 times ranked record for IGARCH (IGARCH) model. General speaking IGARCH model is the preferred model for forecast the intraday volatility according to the value of root mean squared error. And the EGARCH model can be the alternative model. GARCH $(1,1)$ model has better performance on the ultra and 10 minutes volatility forecast, however in another frequency volatility forecast has low performance. Which means that GARCH $(1,1)$ model could not be the better model for using in really market. EGARCH model had great performance on both Ultra and 1 minutes frequency volatility estimation, especially in 60 minutes forecast it has lowest root of mean squared error, the model is more accurate in the estimation of 60 frequency. Otherwise in the Ultra-frequency estimation, EGARCH got highest value of R square. IGARCH model has better good performance because it was the much 
more accurate model in case of it has three times ranked in lowest root of mean square error. Even though it didn't get higher R square value, however in real market the accurate estimation approach is very important.

Table 5 presents the result of out of same data. From the result we know that EGARCH model is 5 times ranked in best model, and IGARCH model has 5 times great ranking as well. Compare with EGARCH and IGARCH models in out sample estimation, IGARCH model is 4 times ranked in the lowest root of mean square error, which means that IGARCH model is more accurate than other two type of GARCH model. Especially in 60 minutes frequency volatility forecast, IGARCH model had great performance. Otherwise, IGARCH model had great performance on ultra frequency forecast, which mean that IGARCH model is able to capture the ultra market volatility. GARCH $(1,1)$ model has lowest performance on out of sample forecast.

Insert Table 4, Table 5 Here.

\section{IV.Conclusion}

This paper tired to analysis intraday volatility by GARCH series models, the result is that EGARCH model is the best one of intraday volatility estimation in evidence of S\&P500 stock index future market. And IGARCH Model is the better one in in-the-sample estimation. Otherwise the IGARCH model is the preferred for estimation in out-of sample and EGARCH model is the better one. GARCH $(1,1)$ model haven't good performance in the testing. Otherwise, High frequency trading is a most popular trading strategy in current financial market. It has already got huge success from Foreign exchange, future and equity markets. It normally focuses on tick data and intraday volatility and characterized by high number of trades and a lower average gain per trade. Moreover, the crucial factor of high frequency trading successful is that accurate forecast the volatility of asset.

\section{References}

Andersen, T. G., Bollerslev, T. and Lange, S. (1999). Forecasting financial market volatility: sample frequency vis-a-vis forecast horizon, Journal of Empirical Finance, 6, 457-77.

Andersen, T. G., Bollerslev, T., Christoffersen, P. F. and Diebold, F. X. (2005). Volatility forecasting, Working Paper No. 05-011, Penn Institute for Economic Research.Andersen,

T.G., Bollerslev, T., Diebold, F. X. and Ebens,H. (2001). The distribution of realised stock return volatility,Journal of Financial Economics, 61, 43-76.

Andersen, T. G., Bollerslev, T., Diebold, F. X. and Labys, P. (2003). Modelling and forecasting realized volatility, Econometrica, 71, 579-625.

Areal, N. M. P. C. and Taylor, S. J. (2002). The realized volatility of FTSE-100 futures prices, Journal of Futures Markets, 22, 627-48.

Baillie, R. T., Bollerslev, T. and Mikkelsen, H. O. (1996). Fractionally integrated generalised autoregressive conditional heteroscedasticity, Journal of Econometrics, 74, 3-30.

Bollerslev, T. (1986). Generalised autoregressive heteroscedasticity, Journal of Econometrics, 31, $307-27$.

Bollerslev, T. and Mikkelsen, H. O. (1996). Modeling and pricing long memory in stock market volatility, Journal of Econometrics, 73, 151-84.

Brailsford, T. J. and Faff, R. W. (1996). An evaluation of volatility forecasting techniques, Journal of Banking and Finance, 20, 419-38.

Brooks, R. (2007). Power ARCH modelling of the volatility of emerging equity markets, Emerging Markets Review, 8, 124-33.

Christoffersen, P. F. and Diebold, F. X. (2000). How relevant is volatility forecasting for financial risk management, Review of Economics and Statistics, 82, 12-22.

Davidson, J. (2004). Moment and memory properties of linear conditional heteroscedasticity models, and a new model, Journal of Business and Economics tatistics, 22, 16-29.

Ding, Z. and Granger, C. W. J. (1996). Modelling volatility persistence of speculative returns: a new approach, Journal of Econometrics, 73, 185-215.

Ding, Z., Granger, C. W. J. and Engle, R. F. (1993). A long memory property of stock market returns and a new model, Journal of Empirical Finance, 1, 83-106.

Engle, R. F. (1982). Autoregressive conditional heteroscedasticity with estimates of the variance of United Kingdom inflation, Econometrica, 50, 987-1007. 
Engle, R. F. and Bollerslev, T. (1986). Modelling the persistence of conditional variances, Econometric Reviews, $5,1-50$.

Engle, R. F. and Lee, G. G. J. (1999). A permanent and transitory component model of stock return volatility, in Cointegration, Causality and Forecasting: A Festschrift in Honour of Clive W J Granger (Eds) R. F. Engle and H. White, Oxford University Press, Oxford.

Evans, P. and McMillan, D. G. (2007). Volatility forecasts: the role of asymmetric and long-memory dynamics and regional evidence, Applied Financial Economics, 17, 1421-30.

Franses, P. H. and van Dijk, D. (1996). Forecasting stock market volatility using (non-linear) GARCH models, Journal of Forecasting, 15, 229-35.

Granger, C. W. J. (1980). Long memory relationships and the aggregation of dynamic models, Journal of Econometrics, 14, 227-38.

Hansen, P. R. and Lunde, A. (2006). Realised variance and market microstructure noise, Journal of Business and Economic Statistics, 24, 127-61.

Karanasos, M. and Kim, J. (2006). A re-examination of the asymmetric power ARCH model, Journal of Empirical Finance, 13, 113-28.

McMillan, D. G. and Speight, A. E. H. (2007). Weekly volatility forecasts with applications to risk management,Journal of Risk Finance, 8, 214-29.

McMillan, D. G., Speight, A. E. H. and ap Gwilym, O. (2000). Forecasting UK stock market volatility: a comparative analysis of alternate methods, Applied Financial Economics, 10, 435-48.

Nelson, D. B. (1991). Conditional heteroscedasticity in asset returns: a new approach, Econometrica, 59,347-70.

Pagan, A. R. and Schwert, G. W. (1990). Alternative models for conditional stock market volatility, Journal of Econometrics, 45, 267-90.

Poon, S. H. and Granger, C. W. J. (2003). Forecasting volatility in financial markets: a review, Journal of Economic Literature, 41, 478-539.

Poon, S. H. and Granger, C. W. J. (2005). Practical issues in forecasting volatility, Financial Analysts Journal, $31,45-56$.

Quiroga, R. and Sa' nchez, I. (2005). Comportamiento intradı'a de la volatilidad y el volumen del future IBEX 35, Estrategia Financiera, 214, 60-5.

Schwert, W. (1989). Stock volatility and the crash of 87,Review of Financial Studies, 3, 77-102.

Taylor, S. (1986). Modelling Financial Time Series, John Wiley and Sons, New York.

\section{Notes}

Note 1. For more about IGARCH model see Nelson (1990).

Note 2. For more about EGARCH model see Nelson (1991).

Table 1. The result of descriptive statistic

\begin{tabular}{ccccccc}
\hline Time Frequency & Ultra & $1 \mathrm{~min}$ & $5 \mathrm{mins}$ & $10 \mathrm{mins}$ & $30 \mathrm{mins}$ \\
\hline Observations & 1048574 & 1048526 & 1048347 & 1048257 & 1047933 \\
Mean & $5.34 \mathrm{e}-09$ & $-3.15 \mathrm{E}-06$ & $5.45 \mathrm{E}-09$ & $5.04 \mathrm{E}-09$ & $5.54 \mathrm{E}-09$ \\
Median & 0.0000 & 0.0000 & 0.0000 & 0.0000 & 0.0000 \\
Maximum & 0.0011 & $1.66 \mathrm{E}-05$ & $8.04 \mathrm{E}-06$ & $6.11 \mathrm{E}-06$ & $4.21 \mathrm{E}-06$ & 0.0000 \\
Minimum & -0.001 & -0.0331 & $-8.99 \mathrm{E}-06$ & $-6.45 \mathrm{E}-06$ & $-3.87 \mathrm{E}-06$ & $-3.16 \mathrm{E}-06$ \\
Std Dev & $4.64 \mathrm{e}-06$ & 0.0032 & $8.65 \mathrm{E}-07$ & $7.23 \mathrm{E}-07$ & $4.99 \mathrm{E}-07$ \\
Skewness & 0.0111 & 0.0640 & -0.0115 & -0.0442 & -0.0563 \\
Kurtosis & 6.3097 & 1.2311 & 4.3789 & 4.2345 & -0.0882 \\
Jarque-Bera & 4.7861 & 3.3048 & 83085.66 & 66906.07 & 3.0843 \\
(Probability ) & $(0.0000)$ & $(0.0000)$ & $(0.0000)$ & $(0.0000)$ & 51892.99 & $(0.0000)$ \\
\hline
\end{tabular}


Table 2. Unit root testing by ADF and PP models

\begin{tabular}{cccc}
\hline Time Unite & Model & Testing value & P-Value \\
\hline \multirow{2}{*}{ Ultra } & ADF & $-274.6107^{* * *}$ & 0.0001 \\
& PP & $-3.4302^{* * *}$ & 0.0001 \\
1 minute & ADF & $-19.9243^{* * *}$ & 0.0001 \\
& PP & $-3.9721^{* * *}$ & 0.0001 \\
5 minutes & ADF & $-50.3413^{* * *}$ & 0.0001 \\
& PP & $-383.4098^{* * *}$ & 0.0001 \\
\multirow{2}{*}{10 minutes } & ADF & $-41.7706^{* * *}$ & 0.0001 \\
& PP & $327.0710^{* * * *}$ & 0.0001 \\
30 minutes & ADF & $-29.5261^{* * *}$ & 0.0000 \\
& PP & $-241.8626^{* * *}$ & 0.0001 \\
60 minutes & ADF & $-25.8545^{* * *}$ & 0.0001 \\
& PP & $-175.0171^{* * *}$ & 0.0001 \\
\hline
\end{tabular}

***Significant at the $1 \%$ level

Table 3. The result of GARCH testing

\begin{tabular}{ccccc}
\hline Frequency & & ARCH Test & & \\
\hline \multirow{2}{*}{ Ultra } & F-statistic & $130168.3^{* * *}$ & P-value & 0.0000 \\
& OBS*R-squared & 115794.0 & & 0.0000 \\
\multirow{2}{*}{1 minute } & F-statistic & $276411.0^{* * *}$ & P-value & 0.00002 \\
& OBS*R-squared & 202529.0 & & 0.00002 \\
5 minutes & F-statistic & $9327757.0^{* * *}$ & P-value & 0.0000 \\
& OBS*R-squared & 942426.9 & & 0.0000 \\
\multirow{2}{*}{10 minutes } & F-statistic & $13005197.0^{* * *}$ & P-value & 0.0000 \\
& OBS*R-squared & 970066.1 & & 0.0000 \\
30 minutes & F-statistic & $25987237.8^{* * *}$ & P-value & 0.0000 \\
& OBS*R-squared & 1007312.33 & & 0.0000 \\
& F-statistic & $33669215.0^{* * *}$ & P-value & 0.0000 \\
\end{tabular}

$* * *$ significant at $1 \%$ level 
Table 4. Forecast result (In -the-sample)

\begin{tabular}{|c|c|c|c|}
\hline & $R^{2}$ & Likelihood & RMSE \\
\hline \multicolumn{4}{|c|}{ Frequency-Ultra } \\
\hline GARCH(1,1) & 0.00003 & 9077507 & 0.000046 \\
\hline GARCH(1,1)-M & 0.00001 & 9077511 & $0.000037^{*}$ \\
\hline EGARCH & $0.00033^{*}$ & 9077869 & 0.000031 \\
\hline EGARCH-M & 0.00021 & 9099176* & 0.000052 \\
\hline IGARCH & 0.00019 & 9098547 & 0.000041 \\
\hline IGARCH-M & 0.00019 & 9098178 & 0.000039 \\
\hline \multicolumn{4}{|c|}{ Frequency-1 min } \\
\hline GARCH $(1,1)$ & 0.000018 & 9079565 & 0.000061 \\
\hline $\operatorname{GARCH}(1,1)-\mathrm{M}$ & 0.000012 & 9078569 & $0.000049^{*}$ \\
\hline EGARCH & $0.000025^{*}$ & 9077795 & 0.000052 \\
\hline EGARCH-M & 0.000019 & 9099864* & 0.000050 \\
\hline IGARCH & 0.000022 & 9098979 & 0.000053 \\
\hline IGARCH-M & 0.000021 & 9098855 & 0.000052 \\
\hline \multicolumn{4}{|c|}{ Frequency-5 min } \\
\hline GARCH(1,1) & 0.00013 & 13536332 & 0.000865 \\
\hline $\operatorname{GARCH}(1,1)-\mathrm{M}$ & $0.00010^{*}$ & 13536221 & 0.000843 \\
\hline EGARCH & 0.00016 & 13537656 & 0.000801 \\
\hline EGARCH-M & 0.00014 & 13537459 & 0.000795 \\
\hline IGARCH & 0.00018 & $13537884^{*}$ & 0.006448 \\
\hline IGARCH-M & 0.00016 & 13537256 & $0.006232 *$ \\
\hline \multicolumn{4}{|c|}{ Frequency-10 min } \\
\hline GARCH $(1,1)$ & $0.00085^{*}$ & $13728807^{*}$ & 0.000732 \\
\hline $\operatorname{GARCH}(1,1)-\mathrm{M}$ & 0.00082 & 13728791 & 0.000707 \\
\hline EGARCH & 0.00086 & 13720854 & 0.000665 \\
\hline EGARCH-M & 0.00081 & 13720800 & 0.000633 \\
\hline IGARCH & 0.00067 & 13726475 & 0.000591 \\
\hline IGARCH-M & 0.00065 & 13725598 & $0.000557^{*}$ \\
\hline \multicolumn{4}{|c|}{ Frequency-30 min } \\
\hline GARCH $(1,1)$ & 0.00122 & 14174404 & 0.0499 \\
\hline GARCH(1,1)-M & 0.00116 & 14173589 & 0.0463 \\
\hline EGARCH & $0.00130^{*}$ & 14118965 & 0.0236 \\
\hline EGARCH-M & 0.00114 & 14117852 & 0.0208 \\
\hline IGARCH & 0.00108 & 14116657 & 0.0115 \\
\hline IGARCH-M & 0.00104 & 14109638 & $0.0107^{*}$ \\
\hline \multicolumn{4}{|c|}{ Frequency-60 min } \\
\hline $\operatorname{GARCH}(1,1)$ & 0.00877 & 14372799 & 0.7133 \\
\hline $\operatorname{GARCH}(1,1)-\mathrm{M}$ & 0.00852 & 14371082 & 0.7047 \\
\hline EGARCH & 0.00925 & 14379514 & 0.5011 \\
\hline EGARCH-M & 0.00891 & 14378458 & $0.4788^{*}$ \\
\hline IGARCH & 0.01015 & 14589647 & 0.6026 \\
\hline IGARCH-M & 0.01007 & 14586571 & 0.6953 \\
\hline
\end{tabular}


Table 5. Forecast result (Out-of-sample)

\begin{tabular}{|c|c|c|c|}
\hline & $R^{2}$ & Likelihood & RMSE \\
\hline \multicolumn{4}{|c|}{ Frequency-Ultra } \\
\hline GARCH $(1,1)$ & 0.00005 & 9056981 & 0.000033 \\
\hline $\operatorname{GARCH}(1,1)-\mathrm{M}$ & 0.00002 & 9053987 & $0.000021 *$ \\
\hline EGARCH & $0.00067^{*}$ & $9069327^{*}$ & 0.000044 \\
\hline EGARCH-M & 0.00060 & 9067409 & 0.000081 \\
\hline IGARCH & 0.00023 & 9066698 & 0.000047 \\
\hline IGARCH-M & 0.00018 & 9060578 & 0.000065 \\
\hline \multicolumn{4}{|c|}{ Frequency-1 min } \\
\hline GARCH(1,1) & 0.000021 & 9004953 & 0.000057 \\
\hline $\operatorname{GARCH}(1,1)-\mathrm{M}$ & 0.000018 & 9003369 & $0.000050^{*}$ \\
\hline EGARCH & 0.000026 & 9020357 & 0.000055 \\
\hline EGARCH-M & 0.000022 & 9013998 & 0.000048 \\
\hline IGARCH & $0.000028^{*}$ & $9087895^{*}$ & 0.000059 \\
\hline IGARCH-M & 0.000021 & 9078924 & 0.000052 \\
\hline \multicolumn{4}{|c|}{ Frequency-5 min } \\
\hline GARCH(1,1) & 0.00011 & 13426119 & 0.000994 \\
\hline GARCH $(1,1)-M$ & 0.00007 & 13410078 & 0.000872 \\
\hline EGARCH & $0.00019^{*}$ & $13512761^{*}$ & 0.000773 \\
\hline EGARCH-M & 0.00015 & 13510098 & 0.000769 \\
\hline IGARCH & 0.00017 & 13509298 & 0.006301 \\
\hline IGARCH-M & 0.00013 & 13509200 & $0.006298^{*}$ \\
\hline \multicolumn{4}{|c|}{ Frequency-10 min } \\
\hline GARCH(1,1) & 0.00109 & 13366072 & 0.001251 \\
\hline GARCH(1,1)-M & 0.00095 & 13320481 & 0.001108 \\
\hline EGARCH & $0.00113 *$ & $13777456^{*}$ & 0.000923 \\
\hline EGARCH-M & 0.00101 & 13740994 & 0.000874 \\
\hline IGARCH & 0.000933 & 13728920 & 0.000687 \\
\hline IGARCH-M & 0.000884 & 13719987 & $0.000634 *$ \\
\hline \multicolumn{4}{|c|}{ Frequency-30 min } \\
\hline GARCH(1,1) & 0.00148 & 14048689 & 0.0801 \\
\hline $\operatorname{GARCH}(1,1)-\mathrm{M}$ & 0.00123 & 14068971 & 0.0699 \\
\hline EGARCH & 0.00151 & 14035879 & 0.0558 \\
\hline EGARCH-M & 0.00114 & 14048495 & 0.0639 \\
\hline IGARCH & $0.00167^{*}$ & 14096548 & $0.0209 *$ \\
\hline IGARCH-M & 0.00132 & $14109638^{*}$ & 0.0183 \\
\hline \multicolumn{4}{|c|}{ Frequency-60 min } \\
\hline GARCH $(1,1)$ & 0.00904 & 14259769 & 0.8842 \\
\hline GARCH(1,1)-M & 0.00889 & 14223694 & 0.8181 \\
\hline EGARCH & 0.00934 & 14310015 & 0.7915 \\
\hline EGARCH-M & 0.00922 & 14300358 & 0.7558 \\
\hline IGARCH & $0.01007^{*}$ & $14589647^{*}$ & 0.4789 \\
\hline IGARCH-M & 0.00992 & 14586571 & $0.4242 *$ \\
\hline
\end{tabular}




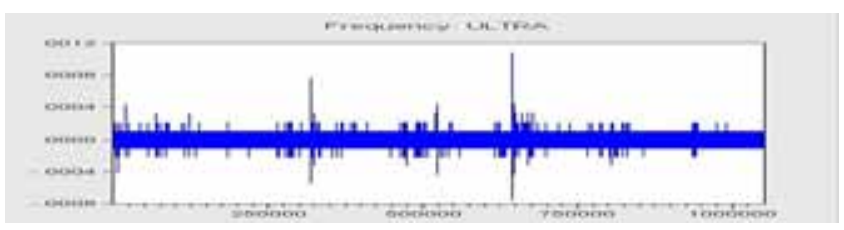

Figure 1. Realized volatility of S\&P 500 index future by ultra-Frequency

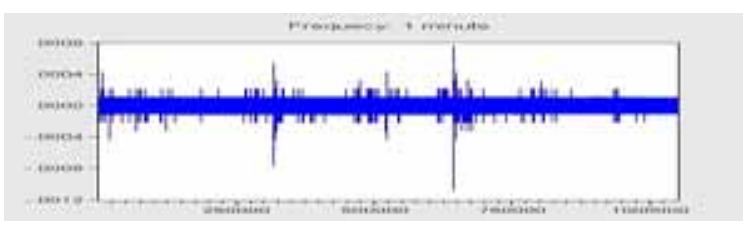

Figure 2. Realized volatility of S\&P 500 index future by 1 minute Frequency

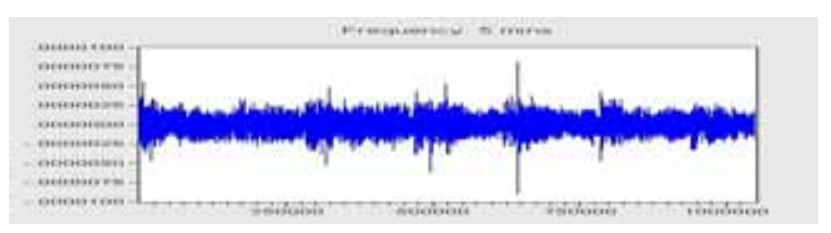

Figure 3. Realized volatility of S\&P 500 index future by 5 minute Frequency

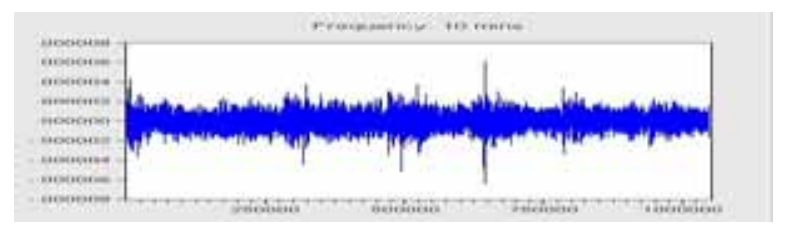

Figure 4. Realized volatility of S\&P 500 index future by 10 minute Frequency

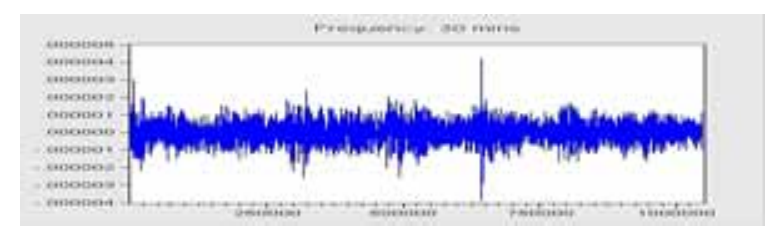

Figure 5. Realized volatility of S\&P 500 index future by 30 minute Frequency

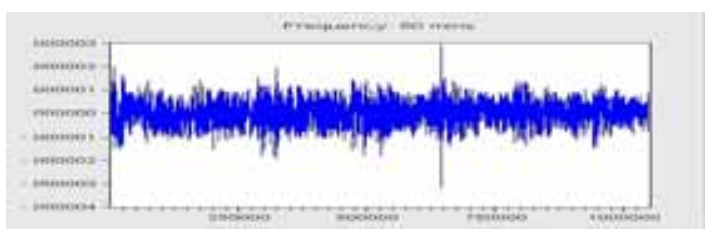

Figure 6. Realized volatility of S\&P 500 index future by 60 minute Frequency 